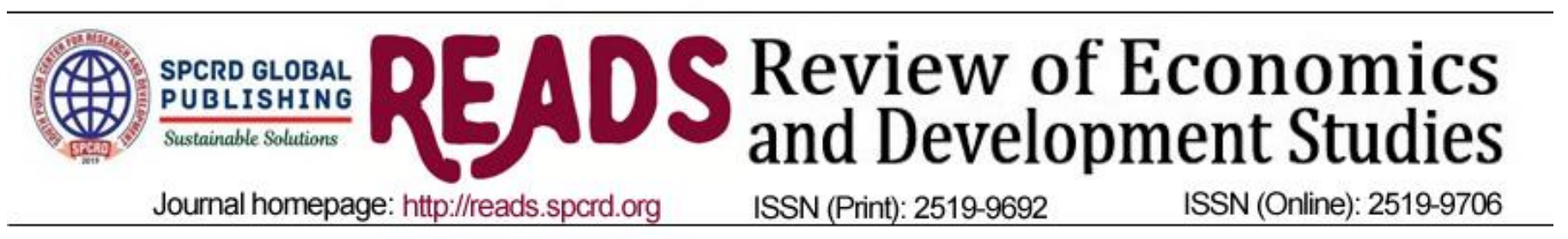

\title{
Mediating Role of Perception of Job Insecurity on the Relationship between Despotic Leadership and Work Engagement: Pakistani Perspective
}

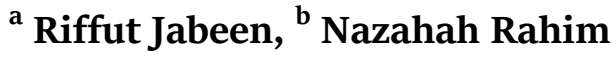 \\ a OYA, Graduate School of Business, University Utara Malaysia, Sintok Campus, Malaysia \\ Email: riffutjabeen@gmail.com \\ ${ }^{\mathrm{b}}$ OYA Graduate School of Business, University Utara Malaysia, Sintok Campus, Malaysia \\ Email: nazahah@uum.edu.my
}

\begin{tabular}{|c|c|}
\hline ETAILS & BSTRACT \\
\hline $\begin{array}{l}\text { History: } \\
\text { Accepted: } 22 \text { May } 2020 \\
\text { Available Online: } 15 \text { June } 2020\end{array}$ & $\begin{array}{l}\text { The importance of work engagement (vigor, dedication, absorption) in } \\
\text { enhancing employee performance is a recognized area of research. In this } \\
\text { competitive and hyper turbulent work environment, disengaged workforce is } \\
\text { costly for any organization. Despite its importance, a very low rate of work }\end{array}$ \\
\hline $\begin{array}{l}\text { Keywords: } \\
\text { Dark Leadership, Despotic } \\
\text { Leadership, Work Engagement, } \\
\text { Perception of Job Insecurity, } \\
\text { Conservation of Resource (COR) }\end{array}$ & $\begin{array}{l}\text { engagement (i.e.5\%) has been found in Pakistan. Drawing on conservation of } \\
\text { resource theory (COR), this paper proposes a conceptual framework to find } \\
\text { out the impact of despotic leadership behavior on work engagement of } \\
\text { employees with a mediating mechanism of employee's perception of job } \\
\text { insecurity. In previous literature little research has been done on despotic } \\
\text { leadership and no study has found on this relationship before. }\end{array}$ \\
\hline
\end{tabular}

JEL Classification:

O17, Q33

DOI: $10.47067 /$ reads.v6i2.205

(C) 2020 The authors. Published by SPCRD Global Publishing. This is an open access article under the Creative Commons Attribution-NonCommercial 4.0

Corresponding author's email address: riffutjabeen@gmail.com

\section{Introduction}

Contemporary organizations are relying on research based directions for managers. These organizations are paying a great attention to the positive behaviors of employees in favor of both financial and non-financial organizations. In developing countries like Pakistan, organization of human resource is a challenge for modern day organizations. Contemporary volatile, uncertain, complex and ambiguous (VUCA) environment is also forcing organizations to keep their employees engaged and to make them competitive (AON Hewitt, 2017). Previous researches show that committed and engaged employees can lead to several advantageous outcomes for an organization e.g. lower turnover intentions (Allen, Shore, \& Griffeth, 2003); greater organizational outcomes (Whitman, Van Rooy, \& Viswesvaran, 2010; Harrison, Newman, \& Roth, 2006); higher level of satisfaction and commitment (Schaufeli \& Salanova, 2007; Schaufeli \& Bakker, 2004; Demerouti Bakker, De Jonge, Janssen, \& Schaufeli, 2001), but employee's investment of energy in work is subjective to their perception about availability, safety and meaningfulness (Rich, Lepine \& Crawford, 2010). 
Gallup (2016) defined that engaged workers are "involved in, enthusiastic about and committed to their work and workplace”. According to Gallup's survey (2016), workers in East Asia are remarkably less engaged as compare to workers in their counterparts in the rest of the world. So, their management/ leadership need to focus on leadership styles, before disengaged workforce harm their competitiveness. Globally, employee engagement rate is $15 \%$. There is remarkably low ratio of engaged workforce in East Asian countries. In Hong Kong only 5\%, China and Japan have 6\%, Taiwan and South Korea 7\%, US, 33\%, UK 8\% and Philippines 36\%. In South Asian countries as compare to India and Sri Lanka, Nepal, Afghanistan, Kazakhstan and Kyrgyzstan; Pakistan has lowest engagement rate i.e. 5\% and approximately $22 \%$ of employees in Pakistan are actively disengaged from their work.

A large number of factors have been highlighted and discussed in the literature that can be considered as a cause of lower work engagement (WE) in Pakistan. It is evident form previous literature that leadership is an influencing process with consequential outcomes on the performance and behaviors of human resource and for organizational advancement (Avolio, 2007). In the wake of worldwide corporate scandals of multi billions economic losses such as Enron (\$74 billion), WorldCom ( $\$ 107$ billion) and Volkswagen ( $\$ 87$ billion); the notion of bad leaders has become a hot topic in research (World Economic Forum, 2015) in context of its impact on employee positive behaviors and useful for organizations (Hoobler \& $\mathrm{Hu}, 2013$ ).

Pakistan has been stunned by disclosures about the improprieties of KASAB Bank, Axact a Karachi-based software company, Punjab Provisional bank and Bank of Punjab scandals alleged involving leadership of the bank. According to Transparency International (2017) report, Pakistan score 117 among 180 countries in corruption and in Asia pacific Pakistan ranks 32 amongst corrupt countries. Moreover, Pakistan has more stressful and challenging work environment (Naseer, Raja, Syed, Donia, \& Dar, 2016; Abbas \& Raja, 2014), high collectivism, uncertainty avoidance and power distance Organization for Economic Co-Operation and Development (OECD , 2013). Employees in such societies show less intention to leave the jobs or organizations. In comparison with individualistic societies, they do not want to disappoint their associates in workplace (Naseer et al., 2016). In this context, study may also yield different results in comparison with countries with individualistic cultures.

Leaders have the capability to inspire their employees to put extra efforts in their work and to achieve organizational goals proficiently and effectively (Asrar-ul-Haq \& Kuchinke, 2016). Organizations vary in relations of their leadership, management styles, culture, quality of communication, levels of trust and respect. House (1995) also asserted that most of the literature on leadership comes from individualistic culture (Geert Hofstede, 2001, 2011) such as North America with a growing need of understanding leadership phenomenon in numerous cultural settings and an empirically grounded theory to describe different conducts of leaders and its value in different cultures. Fewer studies in literature have discussed the undesirable effects of despotic leadership (DL) i.e. a form of negative leadership. According to Luthans, Peterson and Ibrayev (1998), there is more probability of negative leadership behaviors in cultures that have uncertainty avoidance, high power distance and collectivism, such as Pakistan. In such cultures, followers have more tolerance of power differences that portray authoritarianism and oppression (Naseer et al., 2016). Work engagement among employees can be fostered by providing resources, supports and rewards. Leaders who consistently create favorable work environment have more engaged employees (Tims, Bakker, \& Xanthopoulou, 2011). The aim of this conceptual study is also to highlight the effect of a destructive leadership towards WE of employees by exploiting their perceptions of job security (JIS). To the best of researcher's readings, in existing literature the mediating relationship of perception of job insecurity on the association between despotic 
leadership and work engagement has not yet been explored.

\section{Literature Reviewed}

\subsection{The Dark side of Leadership}

"Sometimes the dark side of leadership eclipses the bright side-to the detriment of both the leader and the organization" (Conger,1990).

Leadership phenomenon encompasses the ability of an individual to influence followers in the achievement of organizational goals. Previously, the leadership domain has always been glamorized. According to Glasø, Einarsen, Matthiesen, and Skogstad (2010) ; Schilling (2009), literature has always been highlighting the advantageous and positive effects of leaders on organizations and followers. Comparatively, researchers have largely ignored the dark side of leadership. However, a steady growth has been seen in the past few years' literature on the potential ugly side of leadership (Schaubroeck, Walumba, Ganster, \& Kepes, 2007; Padilla, Hogan, \& Kaiser, 2007; Frost, 2004; Kellerman, 2004; Conger, 1990) showing that leaders can exert harmful influence over their followers (KarakitapogluAygun \& Gumusluoglu, 2013), especially in this global world where the dysfunctional aspects of leaders and top management has become a serious alarm for organizations (Hoobler \& $\mathrm{Hu}, 2013$ ). Under the umbrella of dark side of leadership, numerous terminologies have been used including:

\subsection{Destructive Leadership}

According to Ashforth (1994) there is an understood supposition that incompetent leadership merely mirrors the absence of leadership. However, literature depicts that rather than mere absence of effective leadership, there are variety of different behaviors under the phenomenon of destructive leadership. Schilling (2009) has used an all-encompassing term "negative leadership" as disliked behaviors of leaders extending from ineffective leadership to destructive leadership. Destructive leadership defined by Einarsen et al. (2007) is "The systematic and repeated behavior by a leader, supervisor or manager that violates the legitimate interest of the organization by undermining and/or sabotaging the organization's goals, tasks, resources, and effectiveness and/or the motivation, wellbeing or job satisfaction of subordinates". The definition encompasses all physical and verbal, active and passive, direct and indirect behaviors of destructive leadership. In line with Baumeister et al. (2001), Einarsen et al. (2007) ; Schyns and Schilling (2013) argued that as compare to positive behaviors , negative behavior exert stronger effects on a person's behaviors and actions in social interactions. Therefore, as compared to understanding and augmenting constructive/ positive aspects of leadership, understanding and preventing destructive/damaging leadership is even more important (Zellars, Tepper \& Duffy, 2002; Tepper, 2000; Bies \& Tripp, 1998).

Few studies have been found in literature that have explored the prevalence of destructive leadership behavior in modern organizations (Schat, Frone \& Kelloway, 2006). Hoobler and Brass (2006) found that destructive leadership reduced family wellbeing; provoke intention to quit a job and reduce satisfaction (Tepper, 2000); raise deviant work behaviors (Duffy, Ganster, \& Pagon ,2002); emotional exhaustion, job tension (Harvey, Stoner, Hochwarter \& Kacmar, 2007) and resistant behaviors (Bamberger \& Bacharach, 2006). Taking in view the breadth of the concept, it looks crystal clear that destructive leadership is not just among one type of leadership behavior, but it encompasses a diversity of behaviors instead.

\subsubsection{Destructive Leadership towards Subordinates}

Such leaders threat, demean or humiliate subordinates in public. They expose their subordinates not organization to physical violence (Aryee et al., 2007). 


\subsubsection{Destructive Leadership towards Organization}

Such leaders neglect or aggressively avert organizational goals accomplishment e.g. they work for personal goals rather than organizational goals, damage task accomplishments of subordinates (Conger, 1990); steal time, money and material resources of organization or inspire followers to engage in such deeds and behaviors (Altheide, Adler, Adler, \& Altheide,1978

\subsubsection{Destructive Leadership towards Both, Organization and Subordinates}

According to Kellerman (2004) a comprehensive concept of destructive leadership includes destructive behavior of leaders towards both, followers/subordinates and organization. Such leaders harm both the organization (in terms of resources, e.g. money, time, materials) and the subordinates (in terms of personal resources e.g. positive behaviors).

\subsubsection{Absence of Leadership}

Supportive and disloyal leadership, Liassaze fair leadership and failed leadership (Einarsen et al., 2002, Schilling, 2009) are considered as mere absence of leadership in literature.

\subsection{Despotic Leadership as a form of Destructive Leadership Behavior}

According to Schilling (2009), one prominent example of negative leadership types is despotic leadership, as it embraces the most important characteristics of negative leadership. These leadership behaviors are prominently fixated and motivated on gaining dominance, supremacy, pride, and leader's self-interests, manipulative, bossy, controlling, demanding and unforgiving (McClelland, 1975; Bass, 1990; Howell \& Avolio, 1992; House \& Howell, 1992); demanding obedience from their subordinates, exercise power over them and remain insensitive to the needs of employees (Schilling, 2009); work for their personal benefits and often restrict participation of their subordinates in decision-making process (De Hoogh \& Den Hartog, 2008); low on ethical standards (Aronson, 2001) and lack integrity and moral standards (Naseer et al., 2016); are socially unconstructive share the characteristics of abusive supervision (Martinko, Harvey, Bress, \& Macckey, 2013); weak motivational influence on their followers, that cause lowered inspiration in employees (De Hoogh \& Den Hartog, 2008) and work as a social stressor (Nauman, Fatima, \& Haq, 2018).

\subsection{Work Engagement}

Engagement was entered in the academic wordlist by social psychological work of Khan for the first time in 1990 's. Khan presented the concept of "personal engagement" in his seminal paper. Since that time researcher's interest in engagement mushroomed and multiple researches have been conducted on the conceptualization, definition, theories and measures of engagement (Macey \& Schneider, 2008). Engagement concept has been evolved over the years in literature as:

Personal Role Engagement: According to Khan (1990) engagement involves "the harnessing of organizational member's selves to their work roles; in engagement people employ and express themselves physically, cognitively and emotionally during role performances".

Work or Job Engagement: Another stream of exploration related to engagement takes engagement as, "A positive, fulfilling work related state of mind that is characterized by vigor, dedication and absorption" (Schaufeli, Salanova, Gonzalellez-Roma \& Bakker, 2002, p. 74). The notion of engagement was presented as opposite of burnout. Scaufeli et al. (2002) used the term "work engagement" rather than "personal engagement". Schaufeli and Bakker (2004) also defined work engagement as "the degree of cognitive, physical and emotional connection of employees to their work 
Review of Economics and Development Studies, Vol. 6 (2) 2020, 277 - 288

roles”. Components of Work Engagement: Vigor: denotes mental resilience, great energy, the readiness to capitalize effort, persistence in the time of difficulties, motivation and dedication to put time and effort in work. In essence, WE reflect workers experience at work. Dedication: refers to having an experience of involvement, pride, significance, challenge, enthusiasm, inspiration and meaningful pursuit at work. Absorption: is being focused and absorbed in one's work (Bakker \& Dermouti, 2007). Absorbed in one's work happily means, fully focused to work. One feels difficult to detach him/ herself from work and time passes quickly (Bakker, Schaufeli, Leiter, \& Taris, 2008).

Multidimensional Engagement: In 2006, Saks defined engagement as "a distinct and unique construct consisting of cognitive, emotional and behavioral components that are associated with individual role performance". Engagement involves physical, emotional or cognitive engagement of workers in work roles but it encompasses concurrent involvement of all these forms (Rich et al., 2010) in an associated rather than fragmented manner (Kahn,1990). Work is always a fun, source of contentment and happiness for engaged employees so they do not work hard( Gorgievski, Bakker, \& Schaufeli, 2010).

\subsubsection{Engagement as Management Practice}

In the Human Resource Management (HRM) "Engagement as management practice" is an emerging field and scholars have begun considering "engagement as best friend of Human Resource Management (HRM)". Truss et al. (2014) used the concept of "doing engagement" in contrast of "being engaged "in their research and assert that engagement is subject to "fixing, shrinking, stretching and bending”.

\subsubsection{Engagement as "State like" or "Trait like"}

There is considerable agreement of researcher that it is a higher-order construct comprising emotional, cognitive and behavioral dimensions (Christian, Gharza, \& Slaughter, 2011). There has been a great discussion in psychology, related to the trait-like personality constructs and state-like psychological capacities. Christian et al. (2011) asserts that WE is simultaneously trait-like and statelike construct, being comparatively stable yet fluctuating over time. Bakker (2011) also highlights that as engagement is based on employee's perceptions about work environment and it changes overtime, so it is more state-like.

Literature depicts that adequate rewards and recognition from supervisors (Laschinger \& Finegan, 2005); personal initiative and innovation (Hakanen, Perhoniemi, \& Toppinen-Tammer, 2008); passion about work motivation (May, Gilson, \& Harter, 2004); organizational performance (Harter, Schmidt, \& Hayes, 2002; Whitman et al., 2010); performance at job (Halbesleben \& Wheeler, 2008; Bakker \& Bal, 2010; emotion, effort and energy (Rich, et al., 2010; Christian et al., 2011); performance at group level (Harter, Schmidt, \& Hayes, 2002) ; monetary benefits (Xanthopoulou, Bakker, Demerouti, \& Schaufeli, 2009; Schaufeli \& Bakker, 2008); satisfaction of clients (Salanova, Agut, \& Peiro, 2005); work life balance and meaningful work (Neil Chalofsky \& Vijay Kumar, 2009; CIPD, 2006); job satisfaction (Anaza \& Rutehrford, 2012; Schaufeli \& Salanova, 2007; Schaufeli \& Bakker, 2004; Demerouti et al., 2001); job performance (Wang, Sui, Luthans, Wang, \&Wu, 2014; Kane-Frieder, Hochwarter, \& Ferris, 2014; Bal \& De Lange, 2015) and greater organizational performance (Barrick et al.,2015; Whitman et al., 2010; Harrison et al., 2006) are positively related to engagement while engagement lowers turnover intentions (Allen et al., 2003). So, Bakker et al. (2008) as well as Nair and Salleh (2015) recommended that focus on WE may not only advantageous for employees but also help organizations to gain a competitive advantage in this world of competition. 


\subsection{Relationship between Despotic Leadership and Work Engagement}

Despotic leadership reduces follower's performance, citizenship behaviors, creativity and life satisfaction (Naseer et al., 2016; Nauman et al., 2018); and increase work family conflicts by creating emotional exhaustion and anxiety among employees (Nouman et al., 2018). According to Leary et al. (2013) leader's dysfunctional leadership either overt or covert, direct or indirect distract subordinate's obsession from work to self-preservation and ultimately limit their engagement. Despotic leaders with their unethical, aggrandizing and oppressive behavior work as a social stressor (Nouman et al., 2018). COR theory postulates that people experience threat from a threatened or actual loss of resources (Hobfoll, 1989), in time and energy form (Hobfoll \& hirom, 2001) and as compared to resource gain, resource loss is more noticeable. Any loss in energy resources may cause further resource loss (Nauman et al., 2018). Loss of some resource in one sphere mostly become a cause of resource loss in some other sphere (De Clercq, Haq, Raja, Azeem, \& Mahmud, 2018). Previous application of COR theory in this domain reveals that exposure to destructive leadership styles create stress and cause resource depletion among employees (Whitman, Halbesleben, \& Holmes, 2014; Xu, Loi, \& Lam, 2015; Wu \& Lee, 2016; De Clercq et al, 2018). When individuals face some aggressive situations such as despotic behavior of leaders, they try to cope with these behaviors by investing more attention and energy resulting a loss of energy resources. Therefore, workers who became exhausted due to the depletion of important energy resources at work, particularly due to unethical and self-serving behaviors of leaders, may lose engagement (vigor, dedication, absorption) in their work.

In previous studies, researchers have found that if leaders take care of their employee's interests, employees exhibit higher levels of WE in response (Harter et al., 2002). Following this line of inquiry, researcher believes that despotic leaders show least care to their employees, lack ethical values and norms, fulfill their personal objectives by exploiting their authority and position; resultantly remain unable to convince employees for the achievement of individual and organizational goals (Kanungo ,2001). Followers possibly start questioning norms of effective work behaviors (Naseer et al., 2016), became less engrossed in the work, might show less cooperativeness or willingness to contribute effectively towards organizational progress which results in decrease engagement among followers. Similarly, due to the discretionary nature of WE (Macey \& Schneider, 2008) this study supposed that despotic leadership negatively affects work engagement.

Einarsen et al. (2007) describe destructive behavior of leaders may vary overtime between societies and cultures. Cultures with characteristics of high uncertainty avoidance, high power distance and collectivism like Pakistan (Naseer et al., 2016, OECD, 2013) have higher probability of the arise of despotic leadership behaviors (Naseer et al., 2016). For instance, followers in such cultural context are more likely to tolerate power differences that portray authoritarianism and tyranny (Luthans et al., 1998; Naseer et al., 2016). In line with arguments the study proposes that:

Proposition 1a: $\quad$ Despotic leadership significantly and negatively affects employee vigor.

Proposition 1b: Despotic leadership significantly and negatively affects employee dedication.

Proposition 1c: $\quad$ Despotic leadership significantly and negatively affects employee absorption.

\subsection{Job Insecurity}

According to Hui and Lee (2000), perception of job insecurity (JIS) is perception of employee 
Review of Economics and Development Studies, Vol. 6 (2) 2020, 277 - 288

regarding uncertainty in future and involuntary major change in job from employing organization. Later, Cheng and Chan (2008) as well as Sverke, Hellgren and Näswall (2002) also viewed JIS as high level of uncertainty and threat. It has been defined as a stressor with undesirable crucial consequences for both, employees and employer and further linked with powerlessness (De Cuyper \& De Witte, 2005). According to Sverke and Hellgren, (2002, p. 27), when employees experience job insecurity this doesn't entirely means that they will be laid off. Rather job insecurity denotes to "the anticipation of this stressful event in such a way that the nature and continued existence of one's job are perceived to be at risk". According to the findings of Klandermans, van Vuuren, and Jacobson (1991, p. 44) and Sverke et al. (2002), job insecurity is one of the most significant job stressors as it "influences a much broader range of feelings, attitudes and behaviors than those related simply to performance" and employee sees stress as threat to his/her goals and he/she do not have adequate means to deal with this threat (Lazarus,1991). It is taken as a known phenomenon in organizations (Huang, Zhao, Niu, Ashford, \& Lee, 2013) as it can occur independent of any specific crisis situation (Sverke et al., 2002).

\subsection{Relationship between Despotic Leadership and Perception of Job Insecurity}

Lee et al.(2006) stated that the mainstream research on job security focuses mostly on external factors (such as national unemployment, organizational change) and personality traits (such as negative effectivity ,locus of control).Taking into view the significance of job insecurity, some studies have observed that negative leadership also have adverse effect on perception of job security and proposed that poor and unethical treatment of abusive supervision (Tepper, 200o), workplace bullying (Park \& Ono, 2016; Moore et al., 2012) and transactional leadership (Khuong \&Yen, 2014; Balducci, Cecchin, \& Fraccaroli, 2012) adversely affects job security and decline the life span of work satisfaction and engagement. (Hoel, Cooper, \& Faragher, 2001). According to Jordan, Ashkanasy and Hartel (2002) employees feel negative emotional reactions and stress in situations when organizations fail to provide secure jobs to them and ultimately this stress and negative emotions affect their work efforts. Using COR theory as a basis present study proposes that despotic leadership also work as social stressor on employees and increase the sense of job insecurity among employees.

Proposition 2: Despotic leadership significantly and positively affects employee perception of job insecurity.

\subsection{Relationship between Job Insecurity and Work Engagement}

Perception of job insecurity (JIS) triggers numerous negative job outcomes, for example decrease in WE and performance, job satisfaction, an increased turnover intension, health problems and anxiety (Schreurs, Hetty van Emmerik, Günter, \& Germeys, 2012; Huang et al., 2012; Vander Elst, Van den Broeck, De Witte, \& De Cuyper, 2012; Staufenbiel \& König, 2010; Syerke at al., 2002). Literature have found significant and negative link between JIS perception and performance (Cheng \& Chan ,2008; Gilboa, Shirom, Fried, \& Cooper, 2008). Empirical studies conducted by Loi et al. (2011) and Staufenbiel and König (2010) have found that job insecurity is not related to performance. Generally, uncertainty causes aversive results such as anxieties in individuals. (Sverke et al, 2002) The perception of JIS aroused, when individuals feel objective threat cognitively. Individual variables and social environment affect the cognitive processes of individuals. According to the research findings of Feng, Lu and Siu (2008), JIS strongly negatively affect the performance of employees who have low self-efficacy and organizational citizenship behavior (OCB) (Wang, Lu, \& Lu, 2014). Job insecurity causes lower satisfaction, trust, commitment and engrossment (Cheng \& Chan, 2008), productivity, loyalty and trust (Sverke et al., 2002); organizational support (Ruvio \&Rosenblatt, 1999). Whereas, it increases turnover (De Cuyper, Bernhard-Oettel, Berntson, De Witte \& Alarco, 2008; Smithson \& Lewis, 200o); and resistance to change (Davy et al., 1997). Researchers Stander and Rothmann (2010); Vander Elst, 
Review of Economics and Development Studies, Vol. 6 (2) 2020, 277 - 288

Baillien, De Cuyper, and De Witte (2010) as well as De Cuyper et al. (200) reveal a statistically negative relationship between perception of JIS and WE.

Grounded on COR theory (Hobfoll, 1988, 1998), the study suggested that people are striving to obtain and guard their resources. In literature, COR has also been used to explain the way of investment of resources (Halbesleben \& Bowler, 2008). Following this line of inquiry, the depletion or absence of resources can increase stress and uncertainty such as high job insecurity or burnout.

Moreover, in this stressful and challenging work environment (Abbas \& Raja, 2014; Kausar \& Anwar, 2010) with higher unemployment rate, a job is very necessary for a survival in society like Pakistan. In Pakistan the tendency among employees for searching and applying for parallel jobs and legal suits from employees on organizations (both public and private) is increasing substantially (Rizvi, 2017). In such environment it is more likely that employees work under stress and valorize individual achievements by any means, even at the stake of OCB and job performance (Naseer et al., 2016).Based on aforementioned literature, present study also postulate that work engagement is also an important positive behavior of employees with vigor, dedication and absorption. So, perceptions of job insecurity also negatively affect all the three dimensions of work engagement among workers.

Proposition 3a: $\quad$ Employee perception of job insecurity significantly and negatively effects employee vigor.

Proposition 3b: $\quad$ Employee perception of job insecurity significantly and negatively effects employee dedication.

Proposition 3c: $\quad$ Employee perception of job insecurity significantly and negatively effects employee absorption.

\subsection{Work Engagement a Mediator}

Baillien and De Witte (2009) found that JIS perception fully mediates workplace bullying and organizational change relationship. According to Lazuarus and Folkman (1984), individuals cognitively assess challenges (stressors) that they face in their work lives. To understand the fundamental psychological mechanism, this study applies COR as theoretical model in the relationship between DL and WE via JIS. When individuals encounter despotic leadership behavior, they may begin to assess the solemnity of the consequences of DL. Loss of important job features (job insecurity) may be one of the possible consequences of DL. Mostly, individuals want to develop meaningful and positive relationships with others (Baumeister et al., 2005). So as, even facing a mistreatment for a long period of time, employees (the victims of mistreatment) interpret the negative behavior of leader that arise the feeling of insecurity among employees and harmfully affect their dedication, absorption and vigor. Therefore, DL may affect employee's perception about JIS and consequently arouse the feeling of powerlessness regarding loss of job features and lack of control to change the situation (Vander Elst, De Cuyper, \& De Witte, 2011; De Cuyper \& De Witte, 2007). Hoel and Cooper (2000) discussed that employees who perceive higher level of JIS are less probable to guard themselves against aggressive and unfair behaviors of their co-workers and managers. Some researchers have explored the relationship between DL and its main outcomes (Naseer et al, 2016, Numan, Fatima \& Haq, 2018), but the basic mechanisms of these relationships have been examined in few studies only. This study is adding perception of JIS as possible mediating variable using COR theory. On the basis of COR theory (Hobfoll, 1989) and by integrating the above mentioned hypothesis of direct effects between constructs, present study proposed that perception of JIS mediates the relationship of exogenous and endogenous variables. Amalgamating the aforementioned arguments, the study proposes that. 
Proposition 4a. Employee perception of JIS mediates the relationship between despotic leadership and employee vigor.

Proposition 4b. Employee perception of JIS mediates the relationship between despotic leadership and employee dedication.

Proposition 4c. Employee perception of JIS mediates the relationship between despotic leadership and employee absorption.

\section{Proposed Framework}

Based on issues discussed above, the study proposed a frame work that brings perception of JIS as a mediating variable in the relationship between DL and WE constructs.

Figure1: Proposed Framework

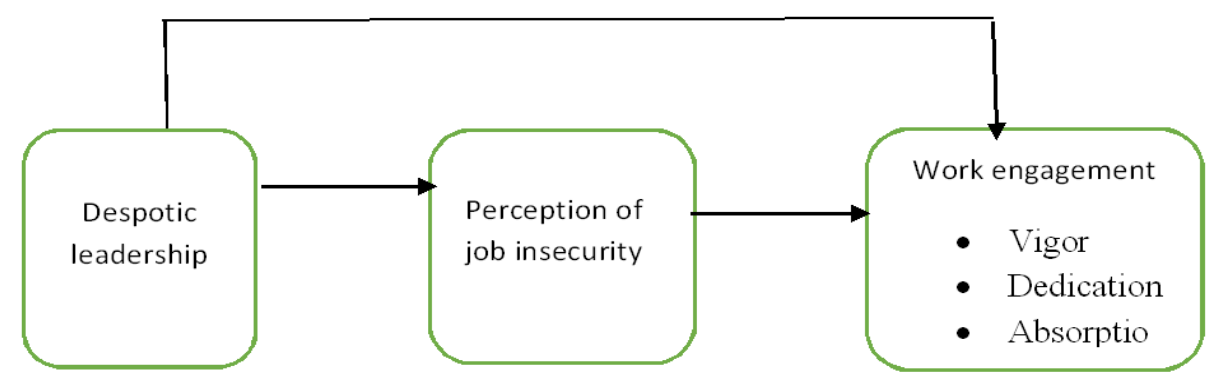

\section{Conclusion and Discussion}

It is widely accepted in literature that leadership is an influencing process with consequential outcomes. On repeated calls by researchers, the study is extending the research on the dark side of leadership by postulating that DL has negative effects on employee's WE through perception of JIS and this perception is one of the main causes of low WE rate in Pakistan. To the best of researcher's readings, the study is adding to the limited literature on negative leadership and is unique because it considers perception of JIS as a potential mediator in this relationship. Study has got excellent support and justifications for proposed relationships where DL had a negative effect on WE and increasing perception of job insecurity in Pakistan.

On the repeated call of researchers, the study makes an important contribution in the negative and specifically in despotic leadership literature on explaining the role of despotic leadership in work engagement and perception of job insecurity. The study also extended the COR theory by proposing a conceptual model including DL, and WE.

Organizations should focus on recruitment policies to prevent hiring of such leaders. Moreover, organizations should organize the training sessions to improve ethical and moral behaviors of the leaders. Feedback from employees about leaders may also be useful to find destructive behaviors of leaders and can be utilized in performance appraisal systems for leader's performance appraisal. Organizations should also take measures to improve employee's perceptions about job insecurity.

\section{Future Directions}

This study also guides future researchers to consider the personal benefits of despotic leaders as self-serving behaviors in organizations and either despotic leaders effect psychological capital of their followers (hope, optimism, resilience and efficacy) through their unethical and corrupt behaviors as negative behaviors have stronger effects on persons as compared to positive events in social interactions (Schyns \& Schilling, 2013). Moreover, another future research avenue may be to explore 
Review of Economics and Development Studies, Vol. 6 (2) 2020, 277 - 288

the impact of DL on ethical climate and justice climate of the organization.

\section{References}

Aasland, M. S., Skogstad, A., Notelaers, G., Nielsen, M. B., \& Einarsen, S. (2010). The prevalence of destructive leadership behaviour. British Journal of Management, 21(2), 438-452.

Abbas, M., \& Raja, U. (2014). Impact of perceived organizational politics on supervisory-rated innovative performance and job stress: Evidence from Pakistan. Journal of Advanced Management Science, 2(2).

Allen, D. G., Shore, L. M., \& Griffeth, R. W. (2003). The role of perceived organizational support and supportive human resource practices in the turnover process. Journal of management, 29(1), 99118.

Asrar-ul-Haq, M., \& Kuchinke, K. P. (2016). Impact of leadership styles on employees' attitude towards their leader and performance: Empirical evidence from Pakistani banks. Future Business Journal, 2(1), 54-64.

Avolio, B. J. (2007). Promoting more integrative strategies for leadership theory-building. American psychologist, 62(1), 25.

Bakker, A. B., \& Bal, M. P. (2010). Weekly work engagement and performance: A study among starting teachers. Journal of occupational and organizational psychology, 83(1), 189-206.

Bakker, A. B., \& Demerouti, E. (2008). Towards a model of work engagement. Career development international, 13(3), 209-222.

Bakker, A. B., Schaufeli, W. B., Leiter, M. P., \& Taris, T. W. (2008). Work engagement: An emerging concept in occupational health psychology. Work \& Stress, 22(3), 187-200.

Bakker, A. B., Emmerik, H. v., \& Euwema, M. C. (2006). Crossover of burnout and engagement in work teams. Work and occupations, 33(4), 464-489.

Bal, P. M., Kooij, D. T., \& De Jong, S. B. (2013). How do developmental and accommodative HRM enhance employee engagement and commitment? The role of psychological contract and SOC strategies. Journal of Management Studies, 50(4), 545-572.

Bamberger, P. A., \& Bacharach, S. B. (2006). Abusive supervision and subordinate problem drinking: Taking resistance, stress and subordinate personality into account. Human Relations, 59(6), 723-752.

Christian, M. S., Garza, A. S., \& Slaughter, J. E. (2011). Work engagement: A quantitative review and test of its relations with task and contextual performance. Personnel psychology, 64(1), 89-136.

De Clercq, D., Haq, I. U., Raja, U., Azeem, M. U., \& Mahmud, N. (2018). When is an Islamic work ethic more likely to spur helping behavior? The roles of despotic leadership and gender. Personnel Review, 47(3), 630-650.

De Hoogh, A. H., \& Den Hartog, D. N. (2008). Ethical and despotic leadership, relationships with leader's social responsibility, top management team effectiveness and subordinates' optimism: A multi-method study. The Leadership Quarterly, 19(3), 297-311.

Demerouti, E., Bakker, A. B., De Jonge, J., Janssen, P. P., \& Schaufeli, W. B. (2001). Burnout and engagement at work as a function of demands and control. Scandinavian journal of work, environment \& health, 279-286.

Einarsen, S., Aasland, M. S., \& Skogstad, A. (2007). Destructive leadership behaviour: A definition and conceptual model. The Leadership Quarterly, 18(3), 207-216.

Glasø, L., Einarsen, S., Matthiesen, S. B., \& Skogstad, A. (2010). The dark side of leaders: A representative study of interpersonal problems among leaders. Scandinavian Journal of Organizational Psychology, 2(2).

Gorgievski, M. J., Bakker, A. B., \& Schaufeli, W. B. (2010). Work engagement and workaholism: Comparing the self-employed and salaried employees. The Journal of Positive Psychology, 5(1), 
Review of Economics and Development Studies, Vol. 6 (2) 2020, 277 - 288

83-96.

Hakanen, J. J., Perhoniemi, R., \& Toppinen-Tanner, S. (2008). Positive gain spirals at work: From job resources to work engagement, personal initiative and work-unit innovativeness. Journal of vocational behavior, 73(1), 78-91.

Halbesleben, J. R., \& Wheeler, A. R. (2008). The relative roles of engagement and embeddedness in predicting job performance and intention to leave. Work \& Stress, 22(3), 242-256.

Harris, K. J., Kacmar, K. M., \& Zivnuska, S. (2007). An investigation of abusive supervision as a predictor of performance and the meaning of work as a moderator of the relationship. The Leadership Quarterly, 18(3), 252-262.

Harrison, D. A., Newman, D. A., \& Roth, P. L. (2006). How important are job attitudes? Meta-analytic comparisons of integrative behavioral outcomes and time sequences. Academy of Management journal, 49(2), 305-325.

Hoel, H., Glasø, L., Hetland, J., Cooper, C. L., \& Einarsen, S. (2010). Leadership styles as predictors of self-reported and observed workplace bullying. British Journal of Management, 21(2), 453-468.

Hofstede, G. (2001). Cultural consequences. Sage Publications, Thousand Oaks, CA.

Hofstede, G. (2011). Dimensionalizing cultures: The Hofstede model in context. Online readings in psychology and culture, 2(1), 8.

Hoobler, J. M., \& Hu, J. (2013). A model of injustice, abusive supervision, and negative affect. The Leadership Quarterly, 24(1), 256-269.

Huang, G. H., Niu, X., Lee, C., \& Ashford, S. J. (2012). Differentiating cognitive and affective job insecurity: Antecedents and outcomes. Journal of Organizational Behavior, 33(6), 752-769.

Kane-Frieder, R. E., Hochwarter, W. A.,\& Ferris, G. R. (2014). Terms of engagement: Political boundaries of work engagement-work outcomes relationships, Human Relations, 67(3), 357382.

Kellerman, B. (2004). Bad leadership: What it is, how it happens, why it matters: Harvard Business Press.

Khan, M. A., \& Ahmad, N. S. A. (2011). Modeling link between internal service quality in human resources management and employees retention: A case of Pakistani privatized and public sector banks. African Journal of Business Management, 5(3), 949.

Leary, T. G., Green, R., Denson, K., Schoenfeld, G., Henley, T., \& Langford, H. (2013). The relationship among dysfunctional leadership dispositions, employee engagement, job satisfaction, and burnout. The Psychologist-Manager Journal, 16(2), 112.

Macey, W., Schneider, B., Barbera, K., \& Young, S. (2009). Talent management essentials. Employee engagement: Tools for analysis, practice, and competitive advantage. In.

Macey, W. H., \& Schneider, B. (2008). The meaning of employee engagement. Industrial and organizational Psychology, 1(1), 3-30.

Martinko, M. J., Harvey, P., Brees, J. R., \& Mackey, J. (2013). A review of abusive supervision research. Journal of organizational behavior, 34(S1).

Naseer, S., Raja, U., Syed, F., Donia, M. B., \& Darr, W. (2016). Perils of being close to a bad leader in a bad environment: Exploring the combined effects of despotic leadership, leader member exchange, and perceived organizational politics on behaviors. The Leadership Quarterly, 27(1), 14-32.

Nauman, S., Fatima, T., \& Haq, I. U. (2018). Does despotic leadership harm employee family life: exploring the effects of emotional exhaustion and anxiety. Frontiers in psychology, 9, 601.

Rich, B. L., Lepine, J. A., \& Crawford, E. R. (2010). Job engagement: Antecedents and effects on job performance. Academy of Management journal, 53(3), 617-635.

Saks, A. M. (2006). Antecedents and consequences of employee engagement. Journal of Managerial Psychology, 21(7), 6oo-619. 
Salanova, M., Agut, S., \& Peiró, J. M. (2005). Linking organizational resources and work engagement to employee performance and customer loyalty: the mediation of service climate. Journal of applied Psychology, 90(6), 1217.

Schaufeli, W., \& Salanova, M. (2007). Work engagement. Managing social and ethical issues in organizations, $135,177$.

Schaufeli, W. B., \& Bakker, A. B. (2004). Job demands, job resources, and their relationship with burnout and engagement: A multi-sample study. Journal of organizational behavior, 25(3), 293315 .

Schaufeli, W. B., Taris, T. W., \& Bakker, A. B. (2006). Dr. Jekyll or Mr. Hyde: On the differences between work engagement and workaholism.), Research companion to working time and work addiction, $193-217$.

Schat, A. C., Frone, M. R., \& Kelloway, E. K. (2006). Prevalence of Workplace Aggression in the US Workforce: Findings From a National Study.

Schilling, J. (2009). From ineffectiveness to destruction: A qualitative study on the meaning of negative leadership. Leadership, 5(1), 102-128.

Schreurs, B. H., Hetty van Emmerik, I. J., Günter, H., \& Germeys, F. (2012). A weekly diary study on the buffering role of social support in the relationship between job insecurity and employee performance. Human Resource Management, 51(2), 259-279.

Schyns, B., \& Schilling, J. (2013). How bad are the effects of bad leaders? A meta-analysis of destructive leadership and its outcomes. The Leadership Quarterly, 24(1), 138-158.

Tepper, B. J. (2000). Consequences of abusive supervision. Academy of management journal, 43(2), 178-190.

Tepper, B. J., Carr, J. C., Breaux, D. M., Geider, S., Hu, C., \& Hua, W. (2009). Abusive supervision, intentions to quit, and employees' workplace deviance: A power/dependence analysis. Organizational behavior and human decision processes, 109(2), 156-167.

Tims, M., Bakker, A. B., \& Xanthopoulou, D. (2011). Do transformational leaders enhance their followers' daily work engagement? The Leadership Quarterly, 22(1), 121-131.

Whitman, D. S., Van Rooy, D. L., \& Viswesvaran, C. (2010). Satisfaction, citizenship behaviors, and performance in work units: A meta-analysis of collective construct relations. Personnel psychology, 63(1), 41-81.

Wu, W.-L., \& Lee, Y.-C. (2016). Do employees share knowledge when encountering abusive supervision? Journal of Managerial Psychology, 31, 154-168.

Xanthopoulou, D., Bakker, A. B., Demerouti, E., \& Schaufeli, W. B. (2009). Reciprocal relationships between job resources, personal resources, and work engagement. Journal of vocational behavior, 74(3), 235-244.

Xu, A.J., Loi, R., \& Lam, L.W. (2015). The bad boss takes it all: How abusive supervision and leader-member exchange interact to influence employee silence. Leadership Quarterly,26,763-774. 